\title{
Failure Mode and Capacity of FRP and concrete Tube
}

\author{
Jing $\mathrm{Ma}^{1, \text { a }}$, Lingqiang Yang ${ }^{2, \mathrm{~b}}$, Yan Wang ${ }^{2, \mathrm{c}}$ \\ ${ }^{1}$ School of Automation and Electrical Engineering, University of Jinan, Jinan, China 250022 \\ ${ }^{2}$ School of Civil engineer and architecture, University of Jinan, Jinan, Shandong province, China \\ acea_yanglq @ujn.edu.cn, cea_Gaor@ujn.edu.cn b , eo_wangy @ujn.edu.cn ${ }^{c}$
}

Keywords: Failure Mode; tube; test.

Abstract. full scale structural testing was carried out on four (4) concretefilled FRP arch specimens. The model was found to accurately predict the response of the arch members. After initial failure has occurred the arch members retain their stability as well as a significant amount of their initial load carrying capacity. The post-peak behavior of the arch members has been studied by subjecting the specimens to a secondary static test until complete failure was forced. During secondary tests the arch members exhibit considerable ductility and energy absorption capacity.

\section{Introduction}

Fiber reinforced polymer composites, or FRPs, have seen increasing use as concrete reinforcement in recent years. FRPs provide superior corrosion resistance, light weight, tailorable structural properties, and often ease of constructability over traditional steel reinforcements. FRPs have been used for both new construction and rehabilitation of existing structures. Forms of FRP reinforcement for concrete include internal rebars, externally bonded plates or shells, and column wraps. a novel system for cast-inplace concrete bridge construction using inflatable fiber reinforced polymer (FRP) composite arch tubes act as both stay in place formwork and structural reinforcement for concrete. The lightweight tubes may be inflated and formed to virtually any geometry in a lab or on a construction site, quickly placed by hand labor, and filled with concrete to create a high strength, durable, and ductile concrete structure.

\section{Test Setup}

Arch specimens were tested under a single patch load applied vertically downward at the crown. Load was applied to the specimens using a $300 \mathrm{kip}$ Instron servo-hydraulic actuator. The specimens were arranged on simple supports to provide a two-pinned arch configuration. Lateral support for the specimens was provided at two points along the span, approximately $3 \mathrm{ft}$ on either side of the crown. The test setup is shown in Fig.1.

The two-pinned arch is a first-degree statically indeterminate structure. Due to the indeterminacy, internal forces (shears, moments) cannot be calculated analytically using simple statics. In order to provide an experimental procedure for measurement of internal forces, the support setup was designed such that horizontal thrust force could be monitored, eliminating one unknown static degree of freedom and resulting in a determinate structure. Thrust force measurements were taken using a horizontal strut incorporated into the south arch support which was instrumented with strain gages. Using this data and an assumption of symmetry about the crown, all internal forces may be solved for directly.

\section{Failure Mode and Capacity}

The failure mode for all specimens was tensile rupture of FRP at the location of maximum moment, directly below the point of load application. This failure mode is consistent with model predictions. A typical failure region is shown in Fig.2. The failure load and moment for the four specimens are given 
in Table 4.5 along with the model prediction. The mean failure load was 72.0 kip with a COV of $2.55 \%$, this was $4.14 \%$ greater than the predicted value of 69.0 kip.

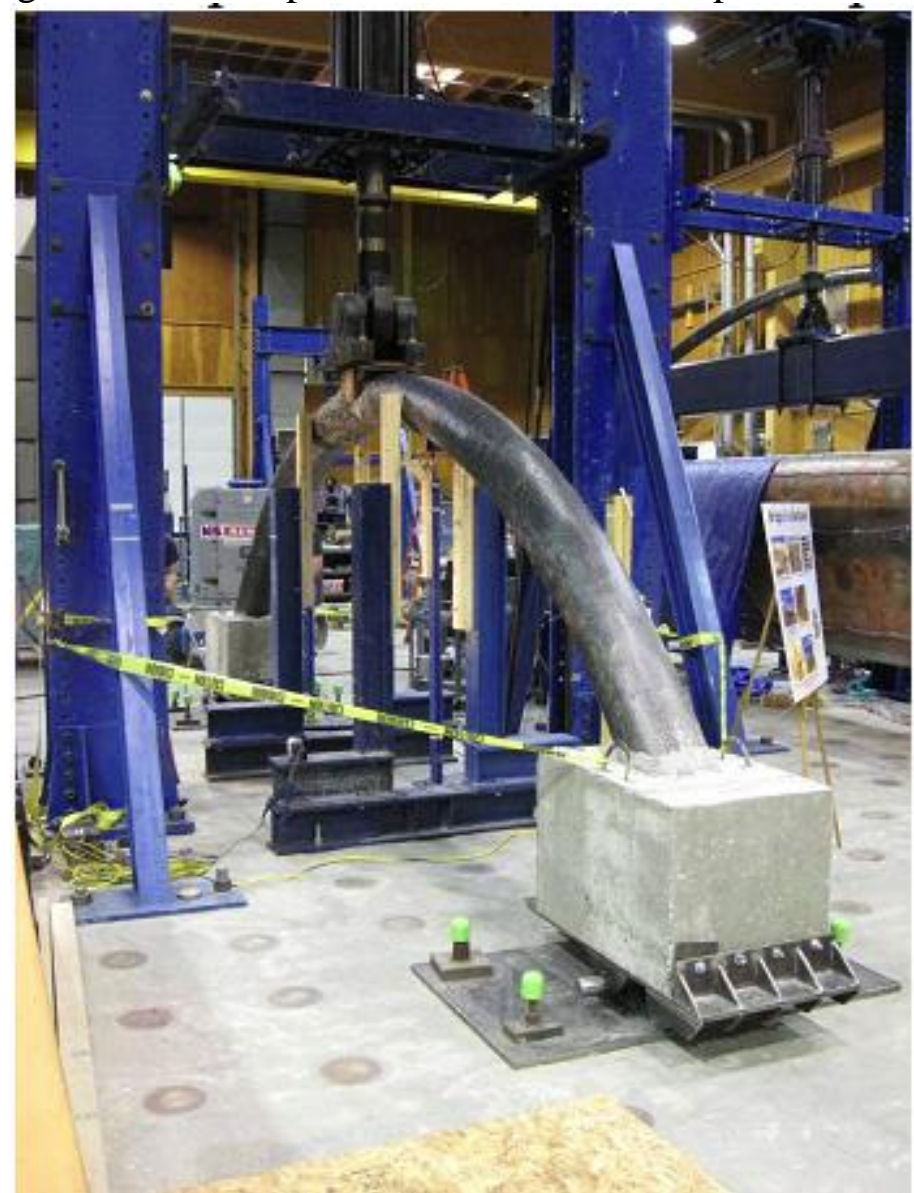

Fig.1 Arch Test Setup

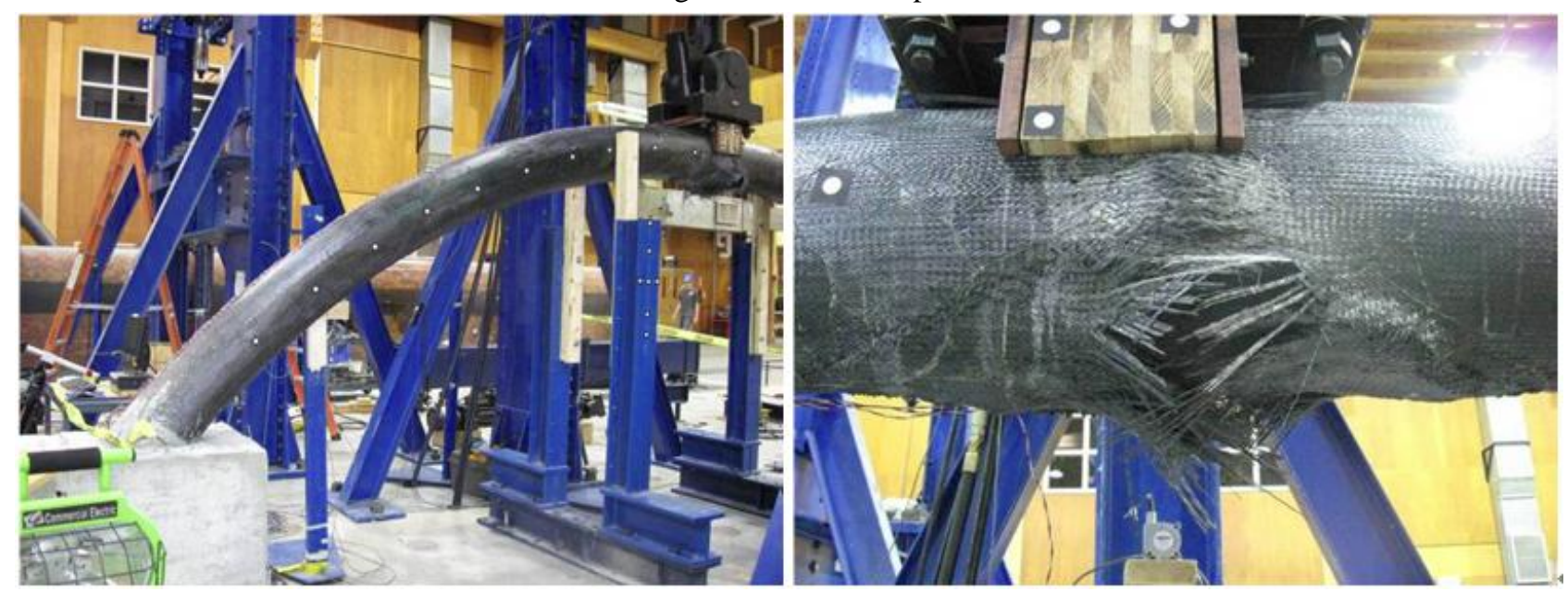

Fig. 2 typical failure region

\section{Post-Peak Testing}

Due to the inherent redundancy of the two-pinned arch system, the specimens maintain stability, as well as a significant portion of their initial capacity after peak loading. In order to asses the post-peak behavior of the members the specimens were subjected to a second stage of loading in which they were continually deflected until complete failure was forced. Of the four arch specimens tested, three were subjected to secondary loading. During secondary tests the arches undergo significant deflections, and ultimately fail in a complete and catastrophic manner. The majority of instrumentation was removed prior to secondary loading to prevent damage during specimen failure. As a result, the only data available from secondary tests is the loaddeflection data from the actuator 
LVDT. After peak loading, the first and fourth arch specimens were unloaded prior to carrying out the secondary static test. It is expected that some residual deformation remained after unloading, however the magnitude of this deformation is unknown as the instrumentation was stopped prior to unloading. The load-deflection curves for the secondary tests are given from the origin for comparison with initial tests. The second specimen was loaded continuously from failure with no unloading and the results are reported as such. Experimental load-deflection response for the initial and secondary tests is given in Fig.3. From the experimental data significant load carrying capacity, deflection, and energy absorption capacity are visible after initial failure occurs and peak loading is achieved.

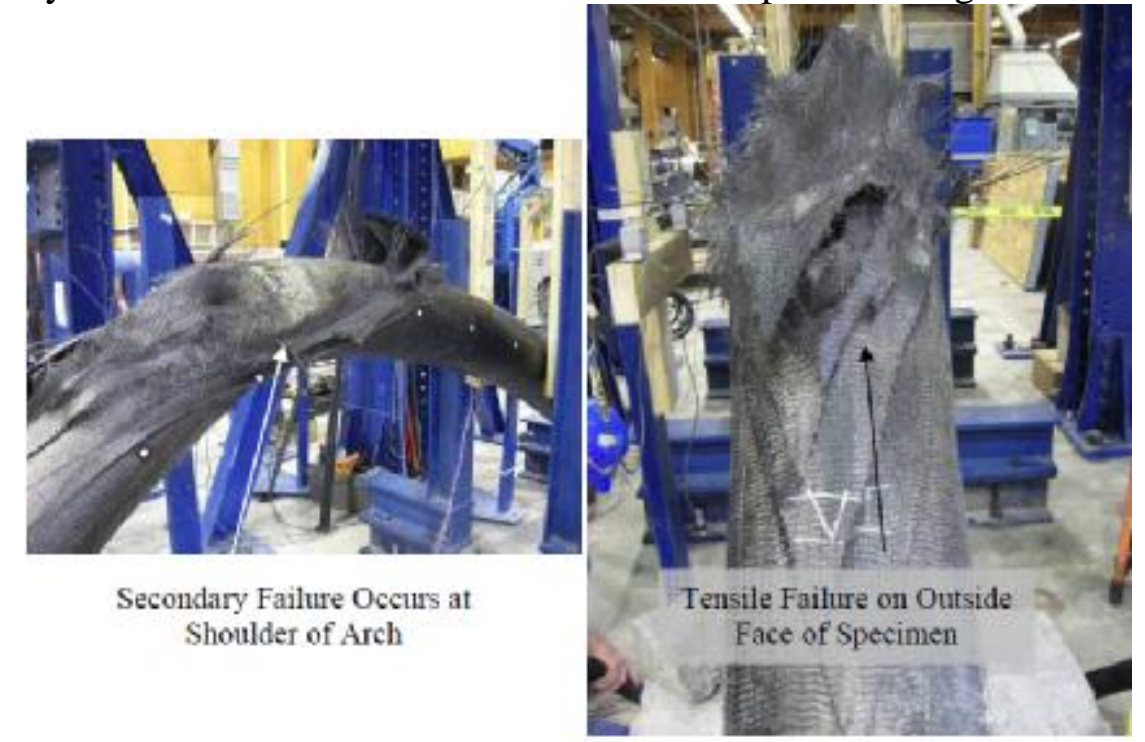

Fig. 3 Arch Specimen Secondary Failure Region

The arch specimen absorbs energy through elastic strain energy and damage accumulation. For this analysis the total energy absorbed by the specimen is assumed to be equal to the external work done by the applied point load acting through its respective displacement (or the area under the load-deflection curve). The initial and secondary energy absorption to failure is given in Table 1 . The average energy to initial failure is $13,810 \mathrm{in} * \mathrm{lb}$. The average energy absorbed from an unloaded condition to secondary failure is $33,000 \mathrm{in} * \mathrm{lb}$, approximately $240 \%$ of the initial. This significant energy absorption capacity results in a structure that is capable of sustaining large amounts of permanent deformation prior to failure. The average secondary failure load was $57.6 \mathrm{kip}, 80 \%$ of the initial peak load.

\section{Post-Peak Modeling}

In order to predict the post-peak behavior of the test specimens, the arch finite element model was modified to reflect a pinned-roller boundary condition at the crown.

This condition is shown in Fig.4. The pinned-roller condition assumes free rotation is possible at the crown, a conservative lower bound as the behavior of the damaged arch section is more similar to a plastic hinge than an ideal hinge, and some rotational stiffness is retained after damage. The amount of rotational stiffness is unknown and difficult to predict as a result of the variable damage state of the crown section, thus this simplifying assumption is assumed adequate for preliminary analysis.

The model predicted and experimental load-deflection curves for secondary testing are shown in Fig.5. The predicted response is much less stiff than the measured response, confirming the plastic hinge behavior of the damaged section. 


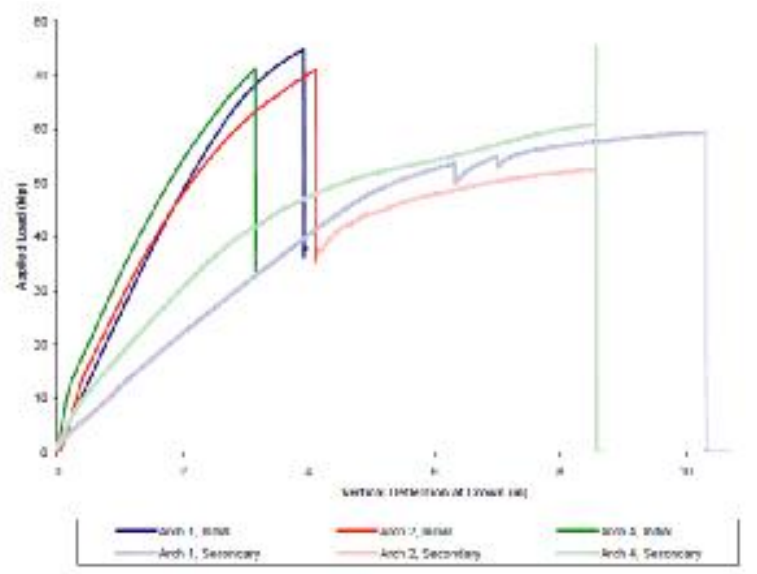

Fig.4. Initial and Secondary Load-Deflection Response

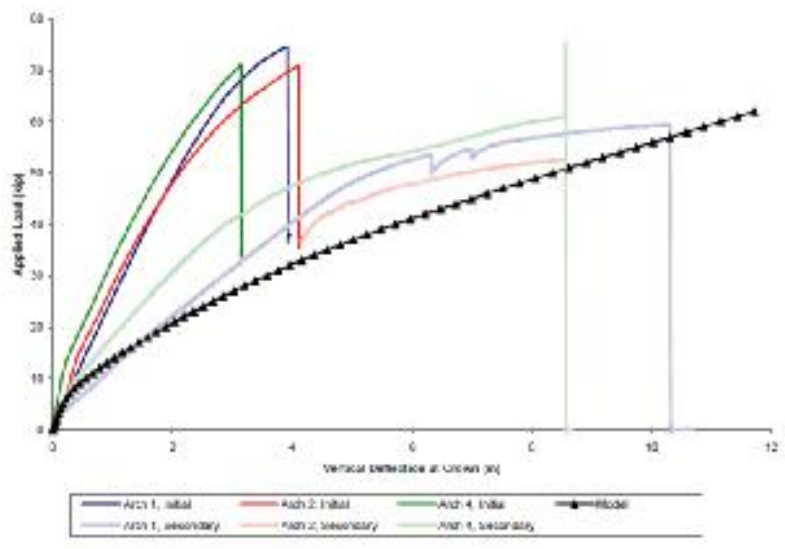

Fig.5 Secondary Load-Deflection Response

Table 1 value of Initial and Secondary Load

\begin{tabular}{llc}
\hline \multirow{2}{*}{ Specimen } & \multicolumn{2}{c}{ Energy Absorption (in*lb) } \\
& To Initial Peak Load & To Secondary Failure \\
\hline Arch 01 & 176,000 & 425,000 \\
Arch 02 & 184,000 & 395,000 \\
Arch 04 & 137,000 & 367,000 \\
Average & 166,000 & 396,000 \\
\hline
\end{tabular}

\section{Conclusions}

After initial failure has occurred the arch members retain their stability as well as a significant amount of their initial load carrying capacity. The post-peak behavior of the arch members has been studied by subjecting the specimens to a secondary static test until complete failure was forced. During secondary tests the arch members exhibit considerable ductility and energy absorption capacity. The post-peak response has been predicted using the arch finite element model by approximating the damaged arch section as an ideal hinge. This assumption provides a conservative lower-bound to the predicted response of the members.

Shear failure was not observed in any of the specimens tested and was therefore not addressed in this research. Shear failure may occur in the form of concrete shear cracking, FRP shear failure, or core-shell bond failure. Alternate spans, cross sections, or geometries may produce shear stresses in members more near to the member shear capacity. In order to effectively characterize all possible failure modes for the arch members the shear capacity should be investigated experimentally through further beam or arch testing of alternate spans and cross section geometries.

\section{Acknowledgements}

This work was financially supported by the Shandong Natural Science Foundation (ZR2014EL038).

\section{References}

[1] Azzi, V. D. \& Tsai, S. W. (1965). Anisotropic Strength of Composites. Experimental Mechanics. 5(9), 283-288.

[2] Becque, J., Patnaik, A. K. \& Rizkalla, S. H. (2003). Analytical Models for Concrete Confined with FRP Tubes. Journal of Composites for Construction. 7(1), 31-38. 